\title{
Data Mining Approach for Amino Acid Sequence Classification
}

\author{
Dr. Sheshang Degadwala \\ Associate Professor, Department of Computer Engineering, Sigma Institute of Engineering, Vadodara, Gujarat, India \\ sheshang13@gmail.com \\ Dhairya Vyas \\ Managing Director, Shree Drashti Infotech LLP, Vadodara, Gujarat, India \\ dhairyavyas@live.com
}

\begin{tabular}{|l|l|}
\hline Article History & \multicolumn{1}{c|}{ Abstract } \\
Article Submission & \multicolumn{1}{|c|}{$\begin{array}{c}\text { Computerized applications are employed all around the world, an enormous amount of } \\
\text { data is collected. The essential information contained in large amounts of data is } \\
\text { Revised Submission } \\
11 \text { September 2021 } \\
\text { Article Accepted } \\
10 \text { October 2021 } \\
\text { Article Published } \\
31 \text { December 2021 } \\
\text { knowledge inside them. The technique of obtaining or mining usable and valuable } \\
\text { knowledge from enormous amounts of data is known as data mining. Text mining, } \\
\text { picture mining, sequential pattern mining, web mining, and so on are all examples of } \\
\text { data mining fields. Sequencing mining is one of the most important technologies in this } \\
\text { field, as it aids in the discovery of sequential connections in data. Sequence mining is } \\
\text { used in a variety of applications, including customers' buying trends analysis, web } \\
\text { access trends analysis, atmospheric observation, amino acid sequences, Gene } \\
\text { sequencing, and so on. Sequence mining techniques are utilized in protein and DNA } \\
\text { analysis for sequence alignment, pattern searching, and pattern categorization. } \\
\text { Researchers are exhibiting an interest in the subject of amino acid sequence } \\
\text { categorization in the field of amino acid sequence analysis. It has the ability to find } \\
\text { recurrent patterns in homologous proteins. This study describes the numerous methods } \\
\text { used by numerous studies to categories proteins and gives an overview of the most } \\
\text { important sequence classification techniques. } \\
\text { Keywords- Data Mining, Amino Acid Sequence, Protein Family, Distance Feature }\end{array}$} \\
\hline
\end{tabular}

\section{Introduction}

Proteins are essential nutrients for human survival. They are a part of bodily tissue that may also be used as a source of energy. They work as machines that produce all living things, including viruses, bacteria, butterflies, jellyfish, plants, and humans. Around 100 trillion cells make up the human body. There are thousands of distinct proteins in each cell. Each cell performs its function as a result of these factors working together. Inside the cell, proteins are like microscopic machines.

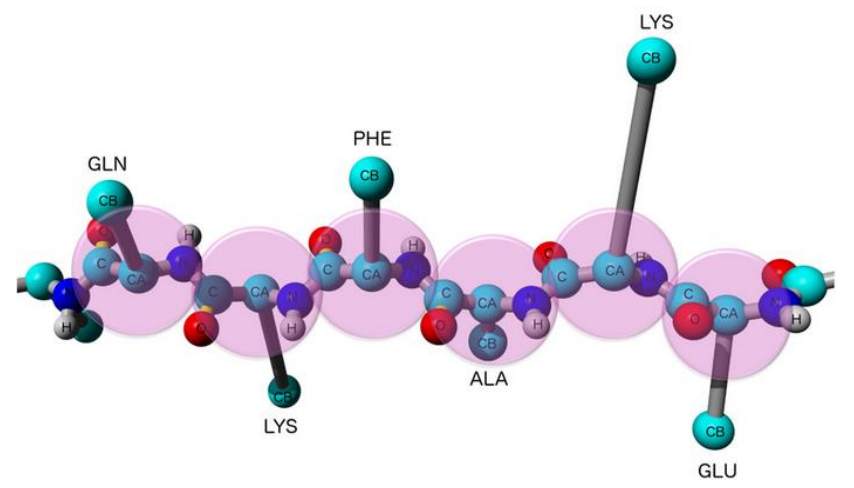

Figure. 1. Primary Structure 

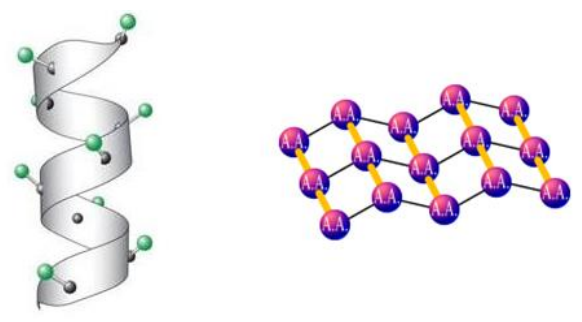

Figure. 2. Secondary Structure

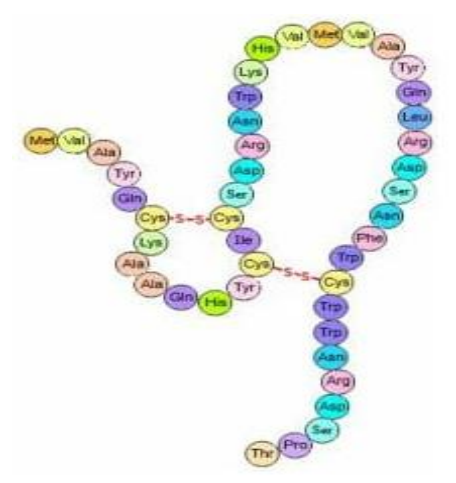

Figure. 3. Tertiary Structure

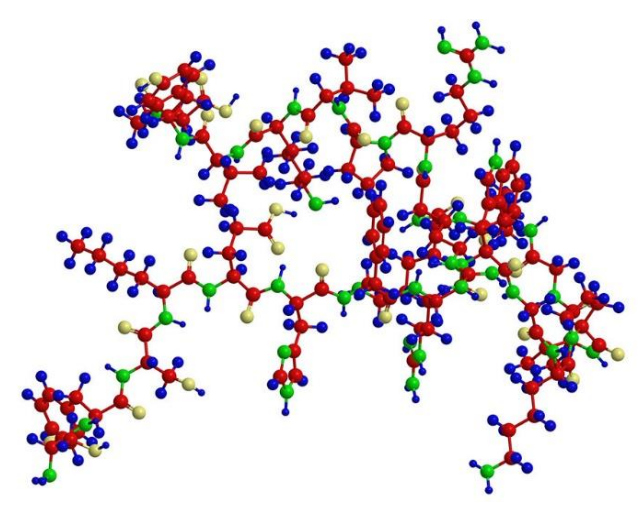

Figure. 4. Quaternary structure

Proteins are composed of tens of lots of smaller components 20 amino acids that are joined together in long chains. The 20 different types of amino acid residues that may be joined to produce a protein are A, C, D, E, F, G, H, I, K, L, M, N, P, Q, R, S, T, V, W, Y. Proteins are also an essential element of an individual's tissues. The four components of amino structure were Primary Structural [Fig.1], Second Structure [Fig.2], Third Structure [Fig.3], and Quaternary Structure [Fig.4].

\section{Related Works}

Dr. Raghav Yadav and Babasaheb Satpute devised a protein arrangement that figured out the separation of each amino acid residue from the residue in [1]. Take the average of all separations of a certain amino acid residue from the initial residue at that position. Prepare a 600X 20 dataset, which means there are 20 features for each amino acid and 600 total amino acids.

Loris Nannia,n, Sheryl Brahnamc, and Alessandra Luminib suggest a novel machine learning system based on combining several amino acid descriptors extracted from various protein representations, such as position specific scoring matrix (PSSM), amino-acid sequences, and secondary structural sequences, in [4]. An ensemble of support vector machines (SVMs) is used to run the system's prediction engine, with each SVM trained on a distinct descriptor. 
The authors of [5] Naveenkumar K S, Mohammed Harun Babu R, Vinayakumar R, and Soman KP primarily rely on earlier Deep learning is being used to classify proteins. To identify the amino acid structure, the properties are extracted using n-gram, Bio-vec, and Prot-v, and then categorised into distinct structures using a deep neural network to find n-dimensional vectors.

Fatima KABLI, Reda Mohamed HAMOU, and Abdelmalek AMINE provide a worldwide framework inspired by the knowledge extraction method from biological data based on association rules in [3]. This framework has three main steps: the first is to extract the descriptors, which was done using the N-Gram technique; the second is to extract the association rules between the proteins components, which was done using the Apriori algorithm; and the third is to choose the relevant rules to classify the unclassified protein. And they compared their classifier to five methods of classification on the WEKA platform, based on the validation tools, on five classes of amino acid extracted from the Uniprot data bank, and got satisfied findings that improved the performance of their protein classifier.

Wenzheng Bao, Yuehui Chen, and Dong Wang proposed a new method to predict the tertiary structure of a amino acid in [6]. The method involves extracting the protein sequence of the amino acid frequencies generalisation dipeptide information hydrophobic combination, using neural networks and flexible neural tree classifier for different the integrated structure classification model, and using neural networks and flexible neural tree classifier for different the integrated structure classification model. To verify the suggested method's efficiency, two benchmark amino acid sequence datasets (640 dataset and 1189 dataset) were chosen as the test data set. The final results suggest that our technique is effective at predicting amino acid structure.

Flexible neutral tree (FNT), a specific tree structure neutral network, has been used as the classification model in the amino acid structures' classification framework by Wenzheng Bao, Dong Wang, and Yuehui Chen in [2]. The impact factors of various feature groups, each of which plays a different role in the model, have been presented in this study. Effect Factors Scaling (IFS) algorithm has been proposed to evaluate distinct impact factors by eliminating redundant information of the selected features to some extent. The 640, 1189, and ASTRAL datasets are used as low-homology amino acid structure benchmark datasets to test the framework's performance.

In [12], Ashish Ghosh and Bijnan Parai attempted to translate the amino acid secondary structure prediction problem to a pattern classification problem and solved it using three low-cost pattern classification algorithms. For window size 11, we employed minimal distance, K-NN, and fuzzy K-NN classifiers, with minimum distance producing the best results. With window size 3, fuzzy K-NN performed better than the other two. We also changed the value of $\mathrm{K}$ and found that the range produced better results. Experiments were carried out with various percentages of training sets, and the results were comparable.

\section{Comparative Study}

\section{TABLE I. Feature Extraction Method}

\begin{tabular}{|c|c|c|}
\hline Method & Advantage & Limitation \\
\hline Distance [1] & $\begin{array}{c}\text {-Simple Calculation } \\
\text {-Easy to implement } \\
\text {-batter accuracy }\end{array}$ & -Amino acid in pattern is require. \\
\hline Parameters [] & $\begin{array}{c}\text {-Numerical output } \\
\text {-Easy to store }\end{array}$ & -Complex to implement \\
\hline Association & -Significant rules among exists ones & - Enormous number of extracted rules \\
\hline Position Specific Scoring Matrix & -Easy Calculation & -Less accurate \\
\hline Multi-scale local descriptor & - Describe overlapping local regions & -Large Feature Dimension \\
\hline
\end{tabular}


TABLE II. Classification Method

\begin{tabular}{|c|c|c|}
\hline Method & Advantage & Limitation \\
\hline NB [1] & $\begin{array}{c}\text { Train quickly. } \\
\text { It is simple to categories. } \\
\text { Handles both continuous and discrete data. } \\
\text { Streaming data is effectively handled. }\end{array}$ & Strong feature independence assumption. \\
\hline $\mathrm{NN}$ & $\begin{array}{l}\text { NN can perform tasks which linear program } \\
\text { cannot. } \\
\text { When element of neural network fails it } \\
\text { continue to work. }\end{array}$ & $\begin{array}{c}\text { They do not classify and cluster data, a lot of chips } \\
\text { and a distributed run-time to train on very large } \\
\text { datasets. }\end{array}$ \\
\hline SVM & $\begin{array}{l}\text { SVM is less complex. } \\
\text { Produce very accurate classifiers. Less over } \\
\text { fitting, } \\
\text { robust to noise. }\end{array}$ & $\begin{array}{l}\text { SVM is binary classifier, to do a multi-class } \\
\text { classification, pair-wise classifications can be used } \\
\text { Computationally expensive, thus runs slow }\end{array}$ \\
\hline Decision Tree & $\begin{array}{l}\text { +It reduces overfitting and is therefore more } \\
\text { accurate. } \\
+ \text { Easy to Implement } \\
\text { works with all types of data. } \\
\text { +Multi classification Support. }\end{array}$ & $\begin{array}{l}\text {-It may not work if the dependent variables } \\
\text { considered in the model are linearly related. } \\
\text { Therefore, one has to remove correlated variable } \\
\text { by some other technique }\end{array}$ \\
\hline $\mathrm{KNN}$ & $\begin{array}{l}\text {-Robust to noisy training data } \\
\text {-Effective if the training data is large }\end{array}$ & $\begin{array}{c}\text { - When it comes to distance learning, it's not } \\
\text { always apparent the sort of distance to utilize or } \\
\text { which characteristic to employ to get the greatest } \\
\text { results. } \\
\text {-the cost of calculation is relatively high }\end{array}$ \\
\hline
\end{tabular}

IV. Proposed Methodology

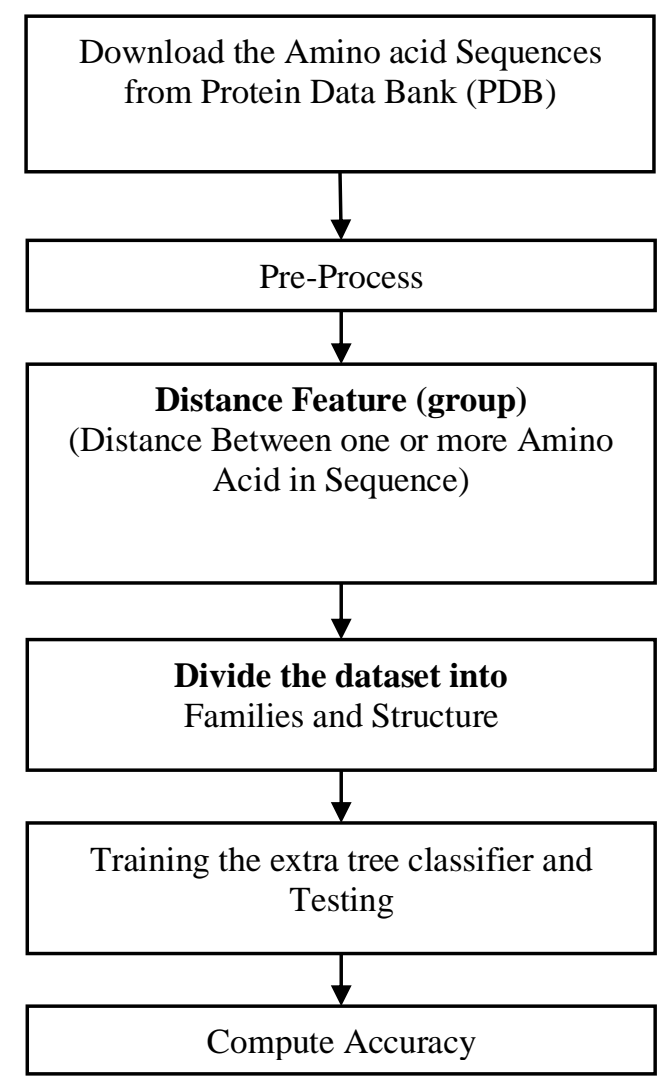

Figure. 5. Proposed Flow 
$1^{\text {st }}$ Step: data on amino acid sequences

Download the whole FUPF class dataset.

$2^{\text {nd }}$ Step: Prepare the data

We'll choose sequences from the table and sample them evenly.

$3^{\text {rd }}$ Step: Obtain N-gram

Patterns of 1-1, 2-2, and 3-3 pair amino acid repeat count.

$4^{\text {th }}$ Step: Labelling

All FUPF classes are labelled using four classes.

$5^{\text {th }}$ Step: Train/Test Data The SVM, KNN ,NB and extra tree classifier are used to train and test data.

$6^{\text {th }}$ Step Result

\section{A. Dataset}

The sequencing of numerous amino acids, as well as their characteristics, are maintained in databases, according to researchers. Protein Data Bank (PDB), UniProt, Swiss-Prot, SCOP, and other well-known databases are examples. These databases can be used to extract amino acid sequences.

The following is an example of a amino acid sequence for the beta chain of haemoglobin:

"PEEKSAVTALWGKVNVDEVGGEALGRLLVVYPWTQRFFESFGDLSTPDAVMGNPKVKAHGKKVLGAFSDGLAHL DNLKGTFATLSELHCDKLHVDPENFRLLGNVLVCVLAHHFGKEFTPPVQAAYQKVVAGVANALA”

\section{B. Modified Distance features Extraction}

For each amino acid sequence in each family, characteristics were extracted. Calculate the distance among each amino acid residue and the first residue in each amino acids sequence. Formerly income the middling of all detachments from the first residue for each amino acid residue. For example, if a residue ' $K$ ' appears 21 times in a sequence, we will compute 21 distances for ' $K$ ', i.e. for each occurrence of ' $K$ ', its distance from the first residue will be computed. The feature value for ' $K$ ' will then be the mean of those 21 distances. As there are 20 distinct amino acid residues that occur many times in a sequence, we will acquire twenty feature values for each amino acid sequence. Prepare a dataset with a size of 600 X 20 (i.e. 20 characteristics per amino acid and 600 total proteins).

\section{Extra Tree Classification}

Extremely Randomized Trees Classifier (Extra Trees Classifier) is a type of ensemble learning technique that generates a classifier performance by combining the results of numerous contra decision forests collected in a "forest." Apart from how well the decision tree algorithm in the forest were created, it is theoretically similar to a Classification Algorithm.
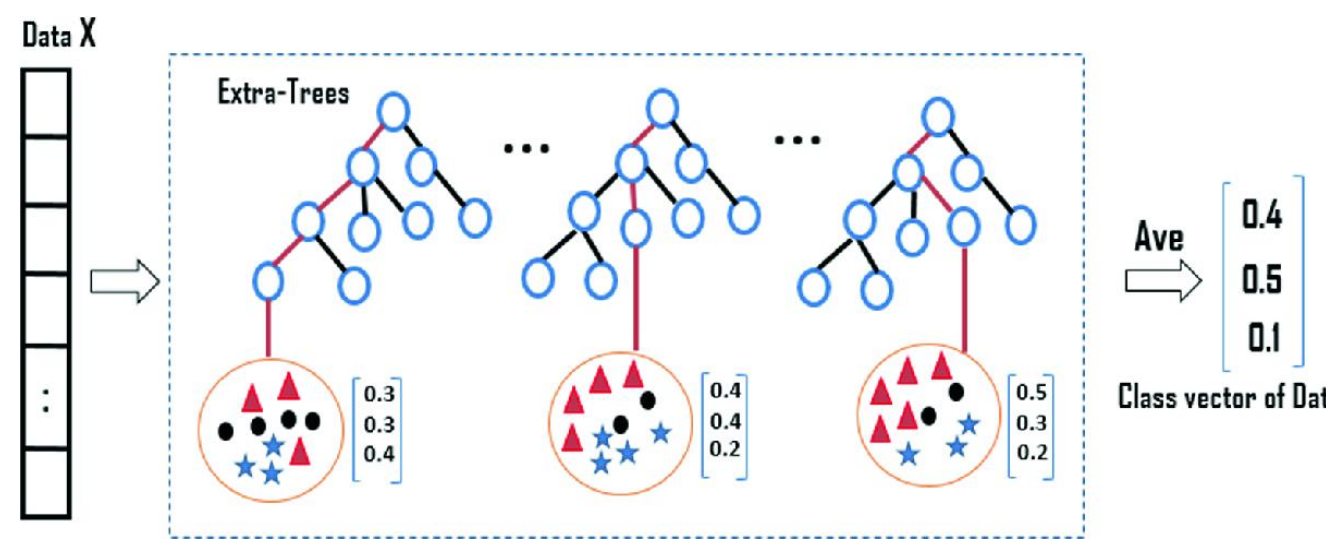

Class vector of Data $X$

Figure. 6. Extra Tree Classification Step 
The Forest of Extra Trees' Choice The original training sample is used to generate all of the trees. The tree would then be provided a representative selection of $\mathrm{k}$ characteristics from the features and functionality at every test node, in which it must pick the best feature to divide the data as per a statistical criterion (typically the Gini Index). This random selection of traits is used to generate several power tree structure.

To step up and play feature extraction using this natural vegetation, the standardised total slight drop in the arithmetical criteria used for the judgement of characteristic of divide (Hdi Indicator if the Gini Coefficient is used in the judgement of characteristic of split) is calculated for each characteristic during the building projects of the forest. This number is known as the Gini Significance of the feature. To carry out feature extraction, each feature is rated by Gini Significance in decreasing order, and the client selects the top k variety of options available on their choices.

\section{Results and Analysis}

\begin{tabular}{|c|c|c|c|c|c|c|c|c|c|c|c|c|c|c|c|c|c|c|c|}
\hline A & B & $\mathrm{c}$ & D & $\mathrm{E}$ & G & H & I & נ & k & L & M & $\mathrm{N}$ & 0 & $\mathrm{p}$ & Q & $\mathrm{R}$ & s & $\mathrm{T}$ & $0 \Delta$ \\
\hline 1 Entry & \multicolumn{19}{|c|}{ Entry nam Length Sequence Protein families } \\
\hline 2095696 & BRD1_HUP & \multicolumn{18}{|c|}{1058 MRRKGRCHRGSAARHPSSPCSVKHSPTRETLTYAQAQRMVEIIEGRLLRIIIFDPLEIILEDDLTAQENSECNSNKENSERPPVCLRTKRHKNNRVKKKNEA_PSAHGTPASASALPEPRVRIVEYSPPSAPRRPPVYYKFIE } \\
\hline 3 Q9NPI1 & BRD7_HUI & \multicolumn{18}{|c|}{651 MGKKHKKHKSDKHLYEEYVEKPLKLLVLVVGGNEVTELSTGSSGHDSSLFEDKNDHDKHKDRKRKKRKKGEKQPGGEKGRKRRRVKEDKKKRDRDRVENEAEKDLQCHAPVRLDLPPEKPLISSLARQEEVEQTPLQEALN } \\
\hline 4060885 & BRDA HUI & \multicolumn{18}{|c|}{1362 MSAEEGPGTRLRNLPVMGDGLETSQMSTQAQAQPQPANAASTNPPPPETSNPNKPKRQTNQLQYLLRVVLKTLWKHQFAWPFQQPVDAVKLNLPDWKIIKTPMDNGTIKKRLENNYYWNAQECIQDFNTMFTN } \\
\hline 5 Q58521 & BRDT_HUI & \multicolumn{18}{|c|}{947 MSLPSRQTAIIVNPPPPEYINTKKNGRLTNQLQYLQRVVLKDLWKHSFSWPFQRPVDAVKLQLPDYTIIKNPMDLNTIKKRLENKYYAKASECIEDFNTMFSNCYLYNKPGDDIVLMAQALEKLFMQKLSQMPQEEQVV } \\
\hline 6015059 & BRD3_HUP & \multicolumn{18}{|c|}{726 MSTATVAPAGIPATPGPYNPPPPEVSNPSKRGGRKTNQLQYMQNVVVKTLWKHQFAWPFYQPVDAIILLLLPDYHKIIINPMDMGTIKKFLENNYYWSASECMQDFNTMFTNCYYYNKPTDDIVLMAQALEKIFLLKI } \\
\hline 7 Qgulf8 & BAZ2B_HL & & 168 MESGER & WALfamily & & & & & & & & & & & & & & & \\
\hline 8 P25440 & BRD2_HUP & \multicolumn{18}{|c|}{801 MLQNVTPHNKLPGEGNAGLGLGPEAAAPGKRIRKPSLLYEGFESPTMASVPALQLTPANPPPPEVSNPKKPGRVTNQLQYLHKVVMKALWKHQFAWPFRQPVDAVKLGLPDYHKIIKQPMDMGTIKRRLENNYYWA } \\
\hline 9 Q9NRL2 & BAZIA_HL & \multicolumn{18}{|c|}{1556 MPLLHRKFWAL family } \\
\hline 10 Qgulf9 & Z2A_HL & \multicolumn{18}{|c|}{1905 MEMEANL WAL family } \\
\hline 11 Q12830 & BPTF_HUN & \multicolumn{18}{|c|}{3046 MRGRRGR PBTF family } \\
\hline 12 Q9NS16 & BRWD1_H & \multicolumn{18}{|c|}{2320 MAEPSSARRPVPLESEYYFLAARYLSAGPCRRAAQVIVQELEQYQLLPKRLLWEGNEHNRSYEELVLSNKHVAPDHLQIICQRIGPMLDKEIPPSISRVTSLLGGGRQSLLRTAKDCRHTVWKGSAFAALHRGRPPEMPVN } \\
\hline 13 P55201 & BRPF1_HU & \multicolumn{18}{|c|}{1214 MGVDFDVKTFCHNLRATKPPYECPVETCRKVYKSYSGIIYYHLYYYDHDNPPPPQQTPLRKHKKKGRQSRPANKQSPSPSEVVSQSPGREVMSYAQAQRMVEVDLHGRVHRIIIIFDNLDVVSEDEEAPEEAPENGSNKEN } \\
\hline 14 Q9U160 & BAZ1B_HL & \multicolumn{18}{|c|}{1483 MAPLLGR WAL family, BAZ1B subfamily } \\
\hline 15 QЯHOEg & BRDB_HUI & \multicolumn{18}{|c|}{1235 MATGTGKHKLLSTGPTEPWSIREKLCLASSVMRSGDONWVSVSRAIKPFAEPGRPPDWFSQKHCASQYSELLETTETPKRKRGEKGEVVETVEDVIVRKLIAERVEEKKKVIKETQERYRRLLRDAELIOAGHMDSRLDELC } \\
\hline 16 Q9H8M2 & BRDG_HUP & \multicolumn{18}{|c|}{597 MGKKHKKHKAEWRSSYEDYADKPLEKPLKLVLKVGGSEVTELSGSGHDSSYYDDRSDHERERHKEKKKKKKKKSEKEKHLDDEERRKRKEEKKRKREREHCDTEGEADDFDPGKKVEVEPPPDRPVRACRTQPAENESTPII } \\
\hline 17 Q6Rl15 & BRW03_H & \multicolumn{18}{|c|}{1802 MAAAPTQIEAELYYLARFLQSGPCNKSAQVVVQELEEHQLIPRRLDWEGKEHRRSFEDLVAANAHIPPDYLKKICERIGPLDKEIPQSVPGVQTLGGVGQSLLRDAKDCKSTLWNGSAFALLLRGRPPELPVNYVKRPN } \\
\hline 18 Q14140 & SRTD2 & \multicolumn{18}{|c|}{314 MLGKGGKRKFDEHEDGLEGKIISPCDGPSKVSYTLQRQTIFNISLMKLYNHRPLTEPSLQRTVLINNMLRRIQEELKQEGSLRPMFTPSSOPTTEPSDSYREAPPAFSHLASPSSHPCDLGSTPLEACLTPASLEEDDDTFCT } \\
\hline 19 Q9ULD4 & BRPF3_HU & \multicolumn{18}{|c|}{1205 MRKPRRKSRQNAEGRRSPSPYSLKCSPTRETLTYAQAQRIVEVDIDGRLHRIIIIVPLLIITEDELIAQDITECNSNKENSEQPQFPGKSKKPSSKGKKKESCSKHASGTSFHLPQPSFRMVDSGIQPEAPPLPAAYYRYIEKPP } \\
\hline 20 Q9UHV2 & SRTD1_HU & \multicolumn{18}{|c|}{236 MLSKGLKRKREEEEEKEPLAVDSWWLDPGHTAVACAPPAVASSSLIFDLSVIKLLHHSLQQSEPDLRHLVLVWNTLRRIOASMAPAAALPPVPSPPAAPSVADNLASSDAALSASMASLLEDLSHEEGSOAPQPLADEGP } \\
\hline 21 Q982н & WDR1_ H & \multicolumn{18}{|c|}{1224 MLPYTVNFKVSARTLTGALNAHNKAAVDWGWQGLLAYGCHSLVVVIDSITAQTLQVEEKHKADVVKVKWARENYHHNIGSPYCLRLLSADVNGKIIVWDVAAGVAQCEIQEHAKPIQDVQWLWNQDASRDLLLAIH } \\
\hline 22092831 & KAT2B_HL & \multicolumn{6}{|c|}{832 MSEAGGA Acetyltransferase family, GCNS subfamily } & & & & & & & & & & & & \\
\hline 23 P51532 & SMCA4_H & \multicolumn{6}{|c|}{1647 MSTPDPPI SNF2/RAD54 helicase family } & & & & & & & & & & & & \\
\hline 24092793 & CBP _HUM & \multicolumn{18}{|c|}{2442 MAENLLGPPNPKRAKLSSPGGSANDSTDFGSLIFDLENDLPDELIPNGGELGLLNGGNLVPDAASKHKQLSELLRGGSGSIINPGIGNVSASSPVQQGLGGQAQGQPNSANMASLSAMGKSPLSQGDSSAPSLPKQAAS } \\
\hline 25092830 & KATZA_HL & \multicolumn{6}{|c|}{837 MAEPSQA Acetyltransferase family, GCNS subfamily } & & & & & & & & & & & & \\
\hline 26 Q86U86 & PB1_HUM. & & 589 MGSKRR & TSPSSSVSGD & DFDDGHHSYSTPGP: & SRRRRRLSN & |LPTVDPI, & ICHELYY & RDYKDE & RLLCELF & APRRRNG & DYYEVV: & PIDLMK & QQKLKME & 'DDVNLL & DFQLLFI & IAKSYYK & SPEYY & KKLWL \\
\hline 27015164 & TIFIA_HUI & & $150 \mathrm{MEV}$ & & & & & & & & LPCLHSF & & & & & & & & AERH \\
\hline $28 \mathrm{P} 21675$ & TAF1 HUN & & $372 \mathrm{MG}$ & & & & & & & & & & & & & & & & \\
\hline & Jiterat & & & & & & & & & & & & & & & & & & \\
\hline
\end{tabular}

Figure. 7. Dataset

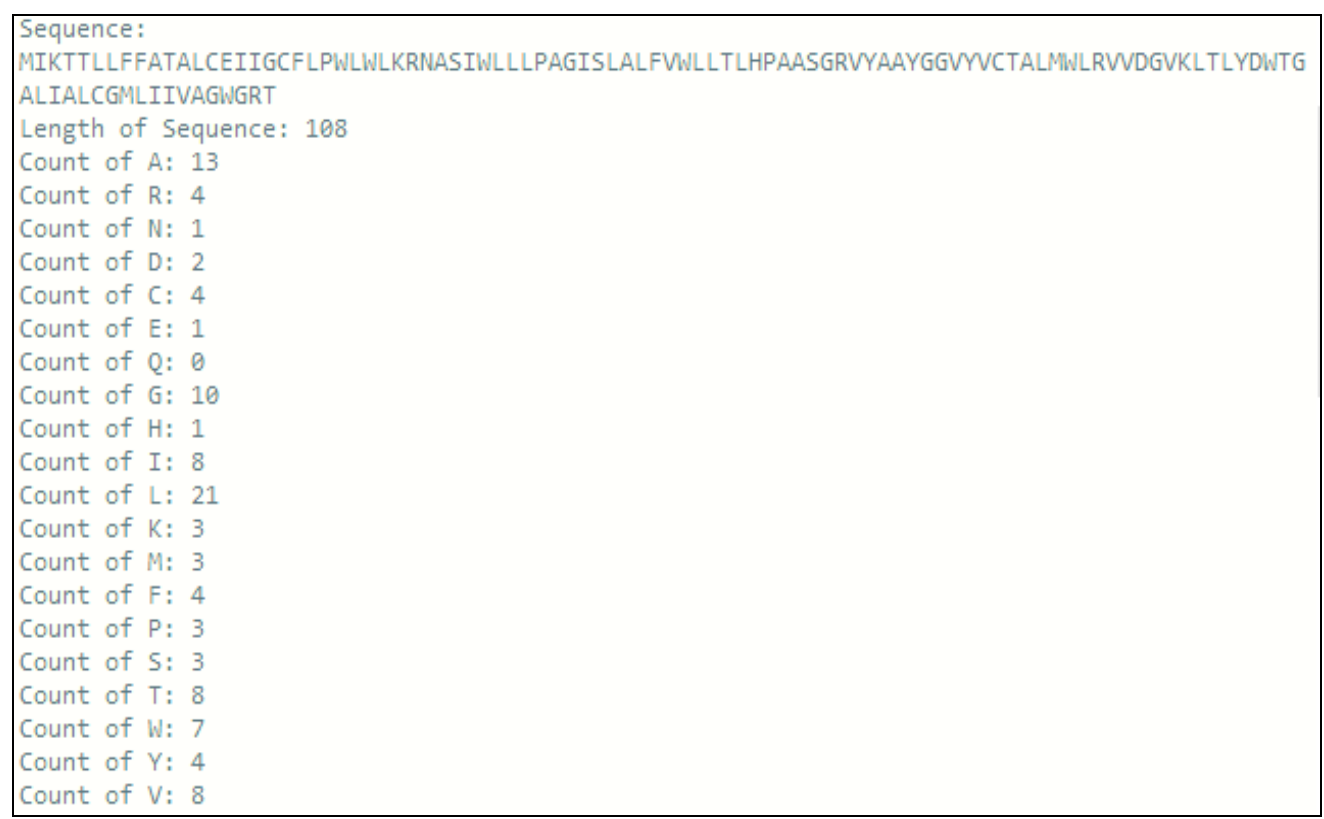

Figure. 8. Amino acid Count 


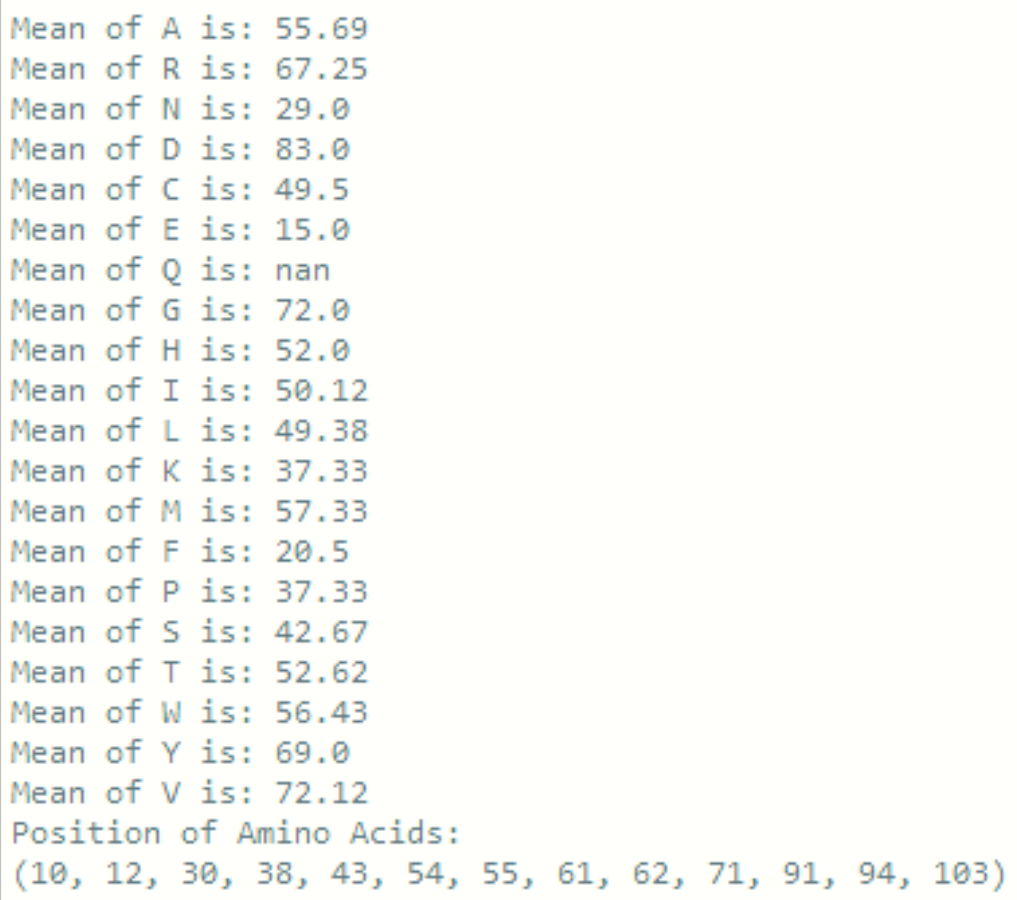

Figure. 9. Mean feature

\begin{tabular}{|c|c|c|c|c|}
\hline \multicolumn{5}{|c|}{$\begin{array}{l}\text { Confusion Matrix: } \\
{\left[\begin{array}{lll}771 & 0 & 5\end{array}\right]} \\
{\left[\begin{array}{lll}0 & 38 & 2\end{array}\right]} \\
{\left[\begin{array}{lll}8 & 0 & 56\end{array}\right]} \\
\text { Accuracy Score : } 91.666666666666666 \\
\text { Report: }\end{array}$} \\
\hline & precision & recall & f1-score & support \\
\hline FUPF 0060 & 0.90 & 0.93 & 0.92 & 76 \\
\hline FUPF0061 & 1.00 & 0.95 & 0.97 & 40 \\
\hline FUPF0102 & 0.89 & 0.88 & 0.88 & 64 \\
\hline accuracy & & & 0.92 & 180 \\
\hline macro avg & 0.93 & 0.92 & 0.92 & 180 \\
\hline weighted avg & 0.92 & 0.92 & 0.92 & 180 \\
\hline
\end{tabular}

Figure. 10. UPF family Classification DT

Figure. 11. Comparative Study

\begin{tabular}{|c|c|}
\hline Classifiers & $\begin{array}{c}\text { Accuracy Proposed Protein } \\
\text { Structure Classification }\end{array}$ \\
\hline SVM & $46.00 \%$ \\
\hline DT & $50.00 \%$ \\
\hline NB & $20.00 \%$ \\
\hline Extra tree & $91.66 \%$ \\
\hline
\end{tabular}




\section{Conclusion}

The inference of a protein's solid construction as of its amino acid sequence is known as protein structure prediction. The diverse structures of proteins FUPF0060, FUPF0061, and FUPF00102, as well as their characteristics extraction techniques, were examined in this study. Amino acid characteristics factor scale, association, Apriorist principles, and other factors are used in research. They employ SVM, DT, NB, and Extra Tree classification techniques for classification. The proposed study on distance combination feature with Extra Tree classier yields a classification result of 91.66 percent.

\section{References}

[1] S. Bankapur and N. Patil, "Enhanced Protein Structural Class Prediction using Effective Feature Modeling and Ensemble of Classifiers," in IEEE/ACM Transactions on Computational Biology and Bioinformatics, doi: 10.1109/TCBB.2020.2979430.

[2] Siddhant College of Engineering, Institute of Electrical and Electronics Engineers. Bombay Section., and Institute of Electrical and Electronics Engineers, 2018 3rd International Conference for Convergence in Technology (I2CT): The Gateway Hotel, XION Complex, Wakad Road, Pune, India. Apr 06-08, 2018.

[3] W. Bao, D. Wang, and Y. Chen, "Classification of Protein Structure Classes on Flexible Neutral Tree," IEEE/ACM Trans. Comput. Biol. Bioinforma., vol. 14, no. 5, pp. 1122-1133, 2017

[4] Hamou, R. M., Kabli, F. and Amine, A. (2017) "New classification system for protein sequences" 2017 First International Conference on Embedded \& Distributed Systems (EDiS).

[5] M. R. Harun Babu and N. K. S, "Protein Family Classification using Deep Learning." bioRxiv preprint first posted online Sep. 11, 201

[6] S. Brahnam, L. Nanni, and A. Lumini "Prediction of protein structure classes by incorporating different protein descriptors into general Chou's pseudo amino acid composition,” J. Theor. Biol., vol. 360, pp. 109-116, Nov. 2014.

[7] Wang D., “A novel protein structure classification model,” no. September, 2015.

[8] A. Charuvaka and H. Rangwala, "Classifying protein sequences using regularized multi-task learning," IEEE/ACM Trans. Comput. Biol. Bioinforma., vol. 11, no. 6, pp.1087-1098, 2014.

[9] K. M. Shawkat Zamil and J. Rahman, "Prediction of Protein-Protein Interaction from Amino Acid Sequence Using Ensemble Classifier," Int. Conf. Comput. Commun. Chem. Mater. Electron. Eng. IC4ME2 2018, pp. 1-4, 2018.

[10]D. Zhang and M. R. Kabuka, "Protein Family Classification with Multi-Layer Graph Convolutional Networks," Proc. 2018 IEEE Int. Conf. Bioinforma. Biomed. BIBM 2018, pp. 2390-2393, 2019.

[11]I. Wohlers, M. Le Boudic-jamin, and H. Djidjev, "LNBI 8542 - Exact Protein Structure Classification Using the Maximum Contact Map Overlap Metric,” pp. 262- 273.

[12] S. Ji et al., "Deep CDpred: Inter-residue distance and contact prediction for improved prediction of protein structure," PLoS One, vol. 14, no. 1, pp. 1-15, 2019.

[13] A. Ghosh and B. Parai, "Protein secondary structure prediction using distance based classifiers," Int. J. Approx. Reason., vol. 47, no. 1, pp. 37-44, 2008.

[14] L. Zhu, S. P. Deng, and D. S. Huang, “A Two-Stage Geometric Method for Pruning Unreliable Links in Protein-Protein Networks," IEEE Trans. Nanobioscience, vol. 14, no. 5, pp. 528-534, 2015.

[15] S. Shatabda, M. A. H. Newton, M. A. Rashid, D. N. Pham, and A. Sattar, "How good are simplified models for protein structure prediction?," Adv. Bioinformatics, vol. 2014, 2014.

[16]D. S. Huang and H. J. Yu, "Normalized feature vectors: A novel alignment-free sequence comparison method based on the numbers of adjacent amino acids," IEEE/ACM Trans. Comput. Biol. Bioinforma., vol. 10, no. 2, pp. 457-467, 2013.

[17]K. M. Shawkat Zamil and J. Rahman, "Prediction of Protein-Protein Interaction from Amino Acid Sequence Using Ensemble Classifier,” Int. Conf. Comput. Commun. Chem. Mater. Electron. Eng. IC4ME2 2018, pp. 1-4, 2018. 